\title{
Variations in Surface Albedo Arising from Flooding and Desiccation Cycles on the Bonneville Salt Flats, Utah
}

\author{
KeVIn M. CRAFT AND JOHN D. HOREL \\ Department of Atmospheric Sciences, University of Utah, Salt Lake City, Utah
}

(Manuscript received 17 August 2018, in final form 12 December 2018)

\begin{abstract}
Desert playas, such as those in northern Utah, form a landscape often in stark contrast to surrounding mountain ranges due to their minimal topographic relief, lack of vegetation, and saline soils. Dry highly reflective halite surfaces, which make up many of the desert playas in northern Utah, are generally characterized by a surface albedo over $40 \%$. However, their albedo can be reduced abruptly to less than $20 \%$ by flooding due to rainfall, runoff from surrounding higher terrain, or surface winds transporting shallow water across the playas. A weather station installed during September 2016 to study the Bonneville Salt Flats (BSF) in northern Utah provides estimates of surface albedo that can be related to cycles of flooding and desiccation of the halite surface. The normalized difference water index (NDWI) derived from the MODIS MOD09A1 land surface reflectance product estimates the fractional coverage of surface water over the BSF. NDWI values computed over 8-day periods from 2000 to 2018 highlight year-to-year and seasonal variations in playa flooding events over the BSF. Periods of playa flooding were observed with both ground-based observations and NDWI with sharp reductions in albedo when the surface is flooded.
\end{abstract}

\section{Introduction}

The basin and range topography of the Bonneville terminal basin in northern Utah leads to the formation of large areas of desert playa surfaces. High reflectivity and small roughness lengths are common characteristics of saline playas (Nicholson 2011). As discussed by Guo et al. (2018), accelerating long-term warming and drying trends in semiarid interior basins of the Northern Hemisphere may be driven in part by feedback processes associated with local land-use and land-cover changes. Atmosphere-land surface feedback processes associated with variations in the albedo of dryland environments may be equally as important as soil moisture feedback processes for simulating droughts (Evans et al. 2017). Although many studies have investigated impacts of ice, snow, and vegetation cover changes on surface albedo, less attention has been placed on changes arising from soil moisture or seasonal water variations (e.g., Chen et al. 2015; Ming et al. 2015; Li et al. 2018).

During synoptically active periods, rainfall, surface runoff from the surrounding terrain, and wind can transform playas in northern Utah into shallow lakes as seen from camera images on the Bonneville Salt Flats

Corresponding author: Kevin M. Kraft, kevin.craft.utah@gmail.com
(BSF; Fig. 1). Such flooding events change fundamental characteristics such as surface albedo, emissivity, aerodynamic resistance, and subsurface temperature and moisture profiles. In addition, they reduce windborne dust transport that often impacts visibility and air quality downwind of metropolitan regions in northern Utah (Steenburgh et al. 2012; Mallia et al. 2017).

Surface albedo ranges from 0.05 to 0.2 for water bodies, with values of $0.20-0.33,0.28-0.44$, and $0.75-0.89$ for dry light sandy soils, dry saline soils, and snowcovered surfaces, respectively (Henderson-Sellers and Wilson 1983). Malek and Bingham (1990) observed sharp reductions in the surface albedo to below 0.25 on the Pilot Valley playa to the northeast of the BSF after a summer thunderstorm. Studies conducted on the Dugway Proving Grounds immediately to the southwest of the BSF documented precipitation events that decreased surface albedo in that area (Malek 2003; Massey et al. 2014, Hang et al. 2016).

Nield et al. $(2015,2016)$ state that the dynamism of playa salt crusts requires greater attention in landatmosphere model parameterizations. They note that playas such as the BSF often undergo multistage cyclic changes: 1) salt crusts grow and ridges form with rates as much as $0.3 \mathrm{~cm}$ week ${ }^{-1}$ on an otherwise flat surface when evaporation rates and upward capillary 

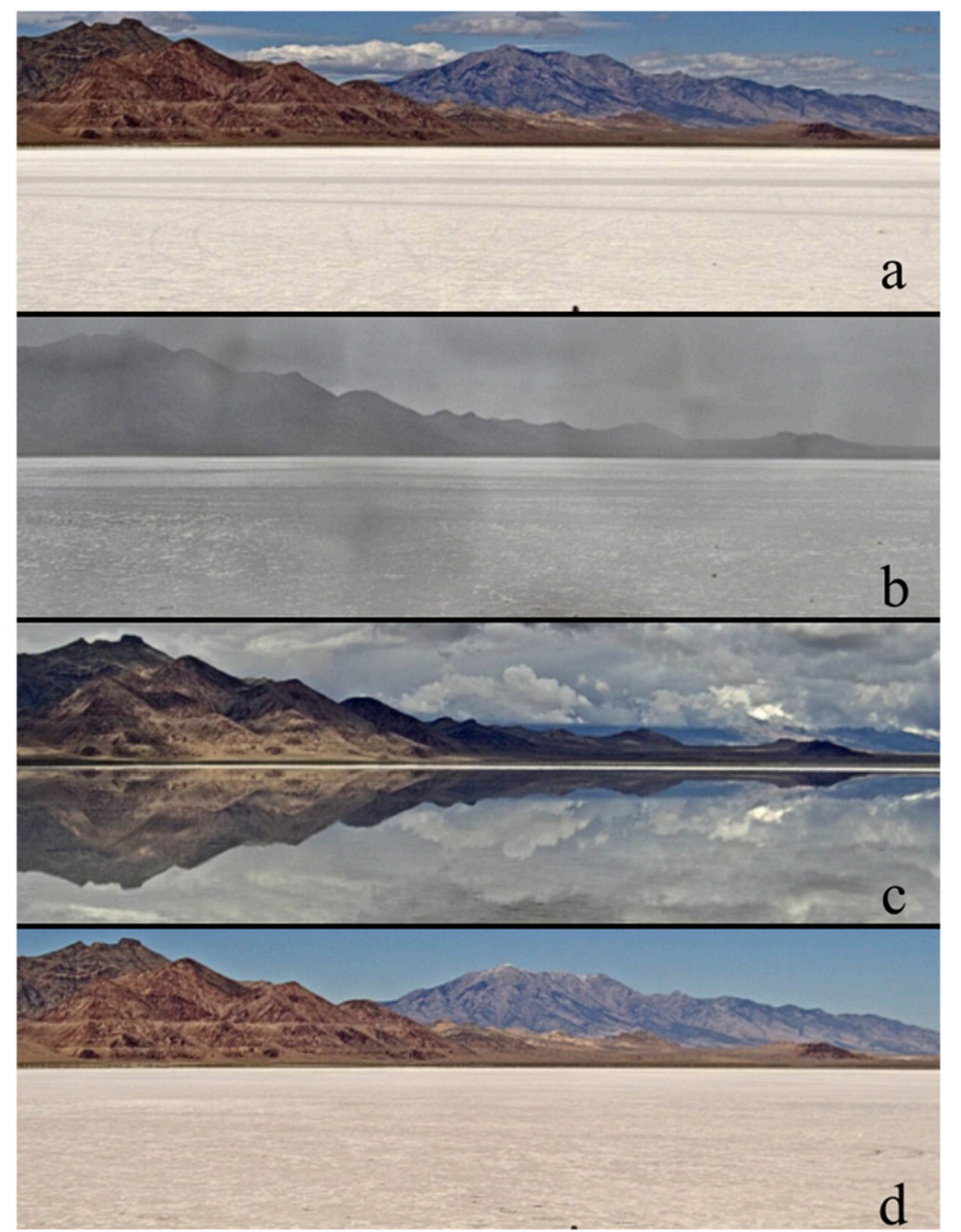

FIG. 1. Surface state during a BSF flooding and desiccation cycle. (a) Prior to precipitation at 1800 UTC 20 Sep 2017. (b) During precipitation event at 2330 UTC 21 Sep 2017. (c) After the formation of an ephemeral lake at 1800 UTC 22 Sep 2017. (d) After the desiccation of the ephemeral lake at 1800 UTC 29 Sep 2017.

transport are high; 2) looser soils and increased surface roughness develop as the crust dries leading to enhanced dust emission; 3 ) further evaporation, wind, and intermittent rainfall harden the crust reducing dust potential; and 4) if the surface becomes covered with water, then the surface is leveled and the cycle may begin again.

Kampf et al. (2005) showed large variations in surface albedo for several types of salt crusts in the Salar de Atacama in northern Chile: smooth dry salt crusts had surface albedo between 0.44 and 0.66 while rugged salt crusts were as low as $0.18-0.25$. Bowen et al. (2017) identified at least five distinct types of halite crusts on the BSF (Fig. 2), all of which are likely to lead to local variations in surface albedo. Widespread flooding events on the BSF occur more frequently during the months from October through May when synoptic and mesoscale storms traverse the region, despite the total annual precipitation in this area being less than $120 \mathrm{~mm}$. The depth and areal extent of any ephemeral lake on the BSF vary with respect to the preexisting surface and soil conditions, amount of precipitation deposited, runoff from the surrounding terrain, and amount of wind-driven transport of water across the 




FIG. 2. Google Earth image of BSF domain. Black inset box defines the domain for MODIS images presented in the results. The red outline defines the area referred to as the BSF domain for this study.

playa surface. During many winter and spring seasons, water coverage over the playa surface cycles from flooding to complete desiccation over short periods from a few days to weeks.

Atmospheric models often incorporate seasonally evolving vegetation and soil moisture or presence of snow cover that affect albedo (Henderson-Sellers and Wilson 1983; Chen and Dudhia 2001; Boussetta et al. 2015). For example, Massey et al. (2014), Blaylock et al. (2017), and Massey et al. (2017) improved the default land-use settings available from the static lookup tables of the Weather Research and Forecast Model to characterize more accurately albedo and other key parameters for dry playa surfaces in northern Utah. However, atmospheric models at present do not consider short-term reductions in albedo arising from occasional periods when a playa surface may become covered by standing water. Even defining the year-to-year variations in the areal extent of the Great Salt Lake is generally poorly treated by operational weather prediction models (Blaylock et al. 2017).

The objective of this research is to document the spatial extent of ephemeral lakes and understand the impact they have on the surface albedo of the BSF in northern Utah. In situ measurements at one location on the BSF since 2016 (BFLAT) and remote sensing imagery from the Moderate Resolution Imaging Spectroradiometer (MODIS) since 2000 are used to investigate the impact of seasonal rainfall and subseasonal rainfall episodes on the surface albedo of the salt crust. Time series of surface albedo and other meteorological variables at high temporal frequency will be examined at BFLAT.
Section 2 describes the methods and datasets used in this research. Section 3 presents the results of the research including the impact of surface moisture and ephemeral lakes on the surface albedo of the BSF and analysis of the remote sensing data used to characterize spatial water distribution on playas. A summary and suggestions for future research are presented in the final section.

\section{Data and methods}

\section{a. In situ observations}

As described by Craft (2018), this research utilized a research-grade automated weather station referred to as BFLAT and located on the BSF in northern Utah $\left(40.78422^{\circ} \mathrm{N}, 113.82946^{\circ} \mathrm{W}\right)$. The following sensors were installed at BFLAT on 27 September 2016: a Vaisala PTB110 pressure gauge; Texas Instruments TR-525USW unheated tipping-bucket rain gauge; Vaisala HMP60 air temperature and relative humidity sensor at $2 \mathrm{~m}$; R. M. Young 05103 anemometer at $3 \mathrm{~m}$; LI-COR LI-200R solar sensors pointing upward and downward measuring between 400 and $1100 \mathrm{~nm}$; and Judd Communications acoustic water level depth sensor. On 6 June 2017, the following modifications to the sensor suite were made: LI-COR solar radiation sensors were replaced by an Apogee SN-500 that provides incoming and outgoing shortwave and longwave radiation, a Campbell Scientific soil temperature sensor was buried at $10 \mathrm{~cm}$, and an Axis Communications web camera was installed. Data were collected at 5-min intervals and made publicly accessible via MesoWest (Horel et al. 2002) and Synoptic API services (https://synopticdata.com/). 
Daily integrated surface albedo is computed as the ratio of the integral of the measured shortwave reflected radiation from the surface ( $\mathrm{SW}_{\text {OUT }}$ ) relative to the integral of the measured incoming shortwave radiation $\left(\mathrm{SW}_{\mathrm{IN}}\right)$ from sunrise to sunset:

$$
\alpha=\frac{\int \mathrm{SW}_{\mathrm{OUT}} d t}{\int \mathrm{SW}_{\mathrm{IN}} d t} .
$$

\section{b. Remote sensing}

This study used data collected by the MODIS instrument on board the Terra satellite. MODIS provides data of Earth's surface for 36 spectral bands ranging from 0.4 to $14.4 \mu \mathrm{m}$ and at spatial resolutions of $250 \mathrm{~m}$, $500 \mathrm{~m}$, and $1 \mathrm{~km}$ (Justice et al. 1998). The swath scanning technique used by MODIS has dimensions of $2330 \mathrm{~km}$ (cross-track) $\times 10 \mathrm{~km}$ (along-track) and views the entire Earth surface every 1-2 days (Barnes et al. 1998; King et al. 1995). The MODIS land science team's land discipline group produces various highlevel land surface products including spectral reflectance and land surface albedo (Justice et al. 1998). The bidirectional atmospherically corrected reflectance product MOD09 (Vermote and Vermeulen 1999) was used in this study.

The initial objective of this research was to validate the MODIS MCD43A3 V006 (NASA LP DAAC 2015b) surface albedo product with ground-based albedo observations taken on the BSF. This product provides surface albedo estimates at 500-m spatial resolution with a daily temporal frequency based on a moving 16-day retrieval period from both the Terra and Aqua satellites (Vermote et al. 2015). Spatial plots of the MCD43A3 shortwave white-sky albedo were generated for the BSF domain because this dataset best represents pyranometer field measurements (Liu et al. 2009; Massey et al. 2017). However, as shown in Fig. 3 , the MCD43A3 product was found to have large areas of missing albedo data across the desert playas in northern Utah. Analysis of quality flags stored in the MCD43A2 (NASA LP DAAC 2015a) product confirmed upward of $70 \%$ of the days used in this study for many of the BSF pixels contained no albedo retrieval, while many of the remaining days were deemed low-quality retrievals. Non-playa land and water surfaces immediately adjacent to playas return a large fraction of days with high-quality albedo data indicating that this is not a large-scale error affecting the entire region but rather is related to the surface characteristics of the playa. Feedback from the NASA product team indicated an awareness of the difficulty in

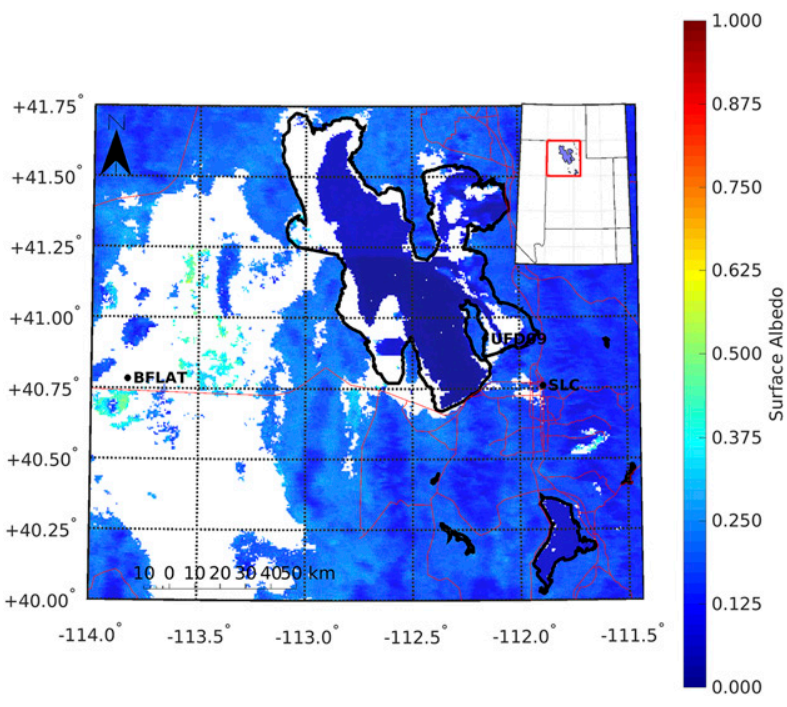

FIG. 3. MCD43A3.006 shortwave white-sky surface albedo for 5 Oct 2017, shaded according to the accompanying scale. No surface albedo values are returned in the white regions, including the BSF.

estimating albedo in this region (C. Schaaf, personal communication, 26 September 2017). Hence, an early objective for this study to validate the MODIS albedo, version 6 , products using in situ measurements over the BSF domain was determined to be not possible at this time.

Despite the lack of surface albedo retrievals for the BSF domain, this study investigated periods of standing surface water on the BSF using the reflectance data from the MODIS MOD09A1 land surface product (NASA LP DAAC 2015c). The MOD09A1 product is a sevenband atmospherically corrected product that estimates the spectral reflectance for each band as if it had been measured at the ground at a 500-m resolution (Vermote et al. 2015). MOD09A1 uses an 8-day composite window to select the best value for each pixel after considering cloud, solar zenith angle, and atmospheric effects. This reduces the temporal frequency of the product to 8 days but the resulting data have reduced noise. This product contains quality data flags within the same data file (Vermote et al. 2015). Quality data were analyzed for the region of interest for this study with the majority of observations showing high-quality data. The entire temporal range of data for the MODIS instrument was used to understand the changes in playa water areal extent during the 18-yr period from 18 February 2000 to 1 May 2018.

To estimate the likelihood that a MODIS pixel was covered by standing water, the normalized difference water index (NDWI) (McFeeters 1996) was used as follows: 


$$
\mathrm{NDWI}=\frac{\rho_{\mathrm{GREEN}}-\rho_{\mathrm{NIR}}}{\rho_{\mathrm{GREEN}}+\rho_{\mathrm{NIR}}} .
$$

The NDWI is a ratio computed from a combination of the near-infrared (NIR $=$ MODIS band $2=\rho_{\text {NIR }}=841-$ $876 \mathrm{~nm}$ ) and green bands (GREEN $=$ MODIS band $4=$ $\left.\rho_{\text {GREEN }}=545-565 \mathrm{~nm}\right)$. NDWI ranges from -1 to 1 with large positive values highlighting standing surface water throughout much of the pixel.

This method has been applied to a variety of remote sensing instruments including MODIS with reasonable accuracy (Doña et al. 2016). Recently, Bowen et al. (2017) used the NDWI with Landsat data to identify and remove pixels covered in water when creating annual area estimates of the salt crust on the BSF as pixels covered in water complicate the calculation of salt crust area.

Figure 2 highlights the BSF domain with the red outline enclosing the $174.75-\mathrm{km}^{2}$ BSF domain examined in this study. NDWI was calculated for each pixel in that domain using the MOD09A1 8-day product for the duration of the MODIS period of record (2000-18). Variations in the areal extent of the salt crust region are common depending on seasonal conditions (Bowen et al. 2017). The subjectively defined BSF domain encompasses the regions most likely to be covered by ephemeral bodies of water after periods of rainfall.

Systematically classifying MODIS pixels with standing water using the NDWI requires a threshold to be set for what constitutes a water-covered pixel. Threshold values are specific to each site based on water and land surface characteristics and the spatial resolution of the imagery as different surfaces absorb light differently (Campos et al. 2012). McFeeters (1996) proposed the threshold for water-covered pixels to be zero. However, examining web camera images from the BSF and histograms of the NDWI over the entire period of record indicated that the threshold needed to be increased to 0.1 for the BSF domain to define conservatively those pixels that are most likely to be extensively covered by water. Pixels with NDWI values less than 0.1 are then considered "dry," even though pixels with values in the -0.1 to 0.1 range may be partially water covered or have high soil moisture content.

\section{Results and discussion}

\section{a. Normalized Difference Water Index}

The MOD09A1 product allows the calculation of the NDWI, which is used to delineate the spatial distribution of water coverage on the playas of northern Utah for 8-day periods from 2000 to 2018. Playa pixels of $\sim 0.25-\mathrm{km}^{2}$ areal extent that have NDWI values greater than 0.1 are deemed to be predominantly covered by standing water with slightly lower values indicating a mix of partial water coverage or high soil moisture content. As shown in Fig. 4 where blue pixels represent surface water, the largest areal extent of water over the BSF domain during the entire MODIS record occurred during the 8-day period from 27 February to 6 March 2005. Extensive water coverage across other playas in northern Utah is also evident at this time. Although the specific depths of any water-covered area cannot be estimated from NDWI, deeper water bodies have higher NDWI values (e.g., approaching 1.0 in the middle of the Great Salt Lake). Low NDWI values $(<-0.25)$ represent vegetative surfaces ranging from grasses and sagebrush to forests as well as the complex land surface types of the metropolitan regions of northern Utah.

Using the NDWI threshold value of 0.1, the fractional area of the BSF domain covered in water $A_{w}$, was calculated. The area $A_{w}$ represents the ratio of the sum of the pixels within the BSF domain that exceeded the NDWI threshold to the total number of pixels in the BSF domain. The value of $A_{w}$ is calculated for each 8-day observation period within the 18-yr MODIS record (Fig. 5). The percentage of BSF area covered by standing water is zero during every summer season with the peak coverage $\left(A_{w} \approx 80 \%\right)$ occurring during the 2004/05 winter season (Fig. 4). Note that $A_{w}>50 \%$ occurred during the 2010-11 and 2016-17 winters as well (Fig. 5). Periods with greater than $50 \%$ water coverage are rare during the last 18 years. The BFLAT weather station observed one of the wettest winters (2016/17) with $A_{w} \approx 55 \%$ and one of the driest winters (2017/18) with $A_{w} \approx 10 \%$.

Averaging all observations over the 18-yr MODIS record for each 8-day calendar period produces a climatology for $A_{w}$ within the BSF domain (Fig. 6). February is the month with the highest values of $A_{w}$ on the BSF with a small secondary peak in April reflecting the frequent occurrence of spring storms crossing the desert. The February maximum in water coverage of the BSF may be influenced by the Salt Laydown Project, which began in 1997 as an attempt to restore the degrading salt crust. The Salt Laydown Project pumps brine from the nearby solar evaporation ponds, used to produce potash [including potassium chloride $(\mathrm{KCl})$ ], to the BSF in late winter (Bowen et al. 2017). The evaporation of the brine beginning in the spring leaves behind salt deposits that thicken the BSF salt crust. Extensive water coverage is unlikely during the hot, predominantly dry summer months. Land speed records for a wide range of vehicles are typically attempted on the BSF during the late summer. By mid-September, the chances of standing 




FIG. 4. NDWI calculated from the MOD09A1 product for 27 Feb-6 Mar 2005 according to the accompanying scale.

water increase as synoptic-scale storms begin to traverse the Great Basin.

The percentages of MODIS observations that exceed the NDWI threshold for each pixel spanning the entire 18-yr record are shown in Fig. 7. The evaporation ponds used for the Salt Laydown Project to the south of the BSF domain have been in operation during this entire period and are evident by the dark blue region in Fig. 7, indicating that nearly all observations of those pixels were identified as water. The narrow strip along the northwestern edge of the BSF domain retains the most water, as it is the lowest elevation within that region. Approximately $15 \%$ of the observations during the 18 -yr period were deemed water covered by the NDWI metric at the automated weather station BFLAT.

\section{b. Albedo changes caused by precipitation}

Periods when the surface is wet or covered by only a thin film of water reduces the brightness of the underlying surface, which leads to lower surface albedo. An example of the cyclic transformation from high-albedo salt crust to low-albedo water surface and finally back to a high-albedo modified salt crust is examined during the 11-day period from 19 to 29 September 2017.

A rainfall event on the BSF of $17.5 \mathrm{~mm}$ at BFLAT (one of the largest of the 2017/18 season) occurred on

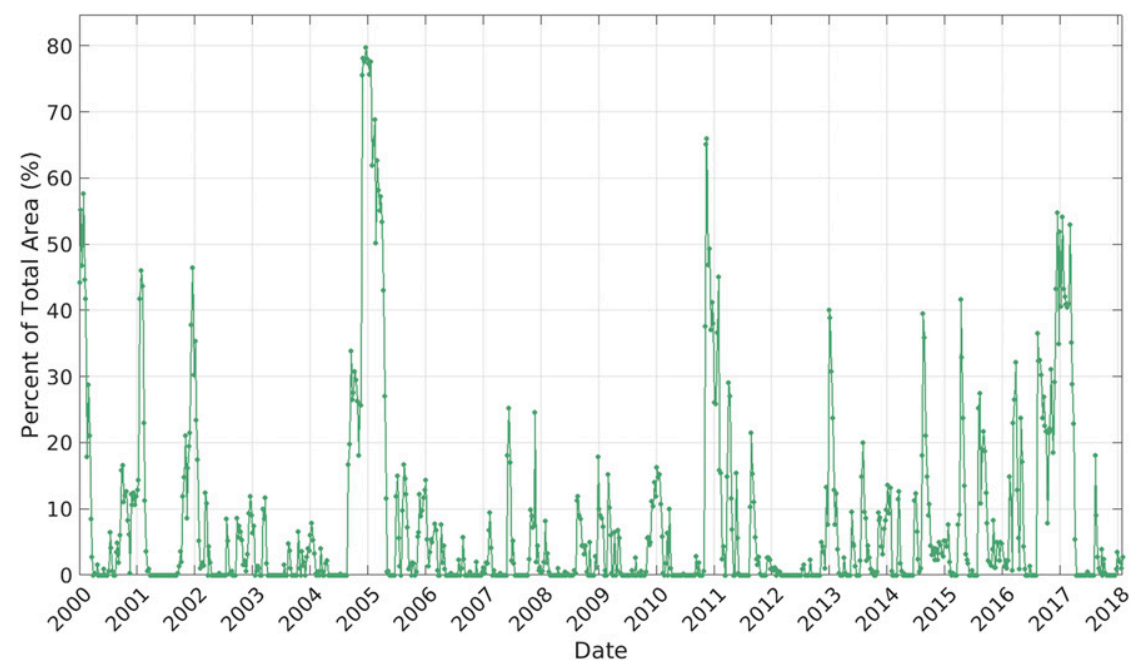

FIG. 5. Fraction of the BSF domain covered by water for January 2000-May 2018 using a 0.1 NDWI threshold applied to the 8-day MODIS MOD09A1 product. 




FIG. 6. Average percentage of total area of the BSF domain covered by water for each 8-day observation period during the year based on a NDWI threshold of 0.1 using the entire 18 -yr MODIS MOD09A1 dataset.

21 September 2017. No substantive precipitation had fallen since the previous spring and the surface was dry. The large area of the BSF and the impermeability of the crust as precipitation falls allows for the formation of ephemeral shallow lakes even without large precipitation accumulations. The camera photos in Fig. 1 highlight the surface state from before the rainfall event on 20 September (Fig. 1a), the day after on 22 September when the water depth was roughly $20 \mathrm{~mm}$ (Fig. 1c), and 7 days later as the surface returned to a highly reflective state (Fig. 1d). The daily integrated values for surface albedo dropped from 0.45 when the surface was dry to 0.22 when the surface was flooded by $20-40 \mathrm{~mm}$ of water (Fig. 8 ). The ephemeral lake persisted in this instance for 5 days at the BFLAT site, after which the water evaporated, infiltrated into the salt crust, and was dispersed by local winds. The albedo by 29 September increased to 0.32 as the surface dried out and the crystalline structure of the salt evolved.

\section{c. Albedo changes forced by water transport across the $B S F$}

The transport of preexisting standing water across the surface by strong winds was observed on several occasions at BFLAT during the 2017/18 period. These types of events, known as shallow water bores (or simply bores hereafter), have been observed on other playas similar to the BSF and may be partially responsible for the transport of heavy stones across the Racetrack Playa in Death Valley, California (Kletetschka et al. 2013).
Shortly after the precipitation event discussed in section $3 \mathrm{~b}$, a convective precipitation event to the north of the station was captured on camera that did not produce precipitation at the BFLAT station. However, strong northwesterly winds transported surface water that remained in the lowest elevations of the BSF from the earlier rainfall episode and that of the convective event toward the station on the evening of 8 October 2017. The acoustic depth sensor at BFLAT estimated a $15-\mathrm{mm}$ depth of the water bore (Fig. 9b). Although surface-level data collected with the acoustic depth sensor require careful quality

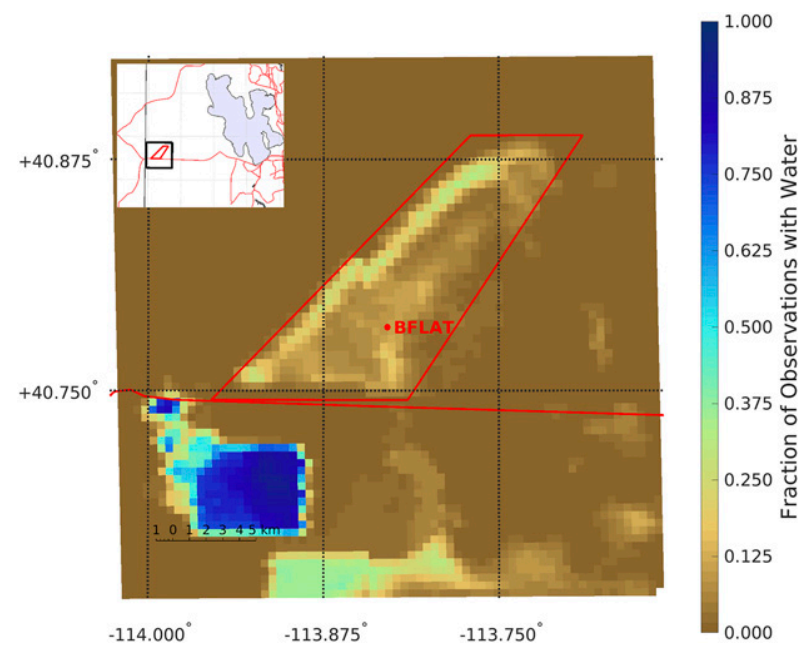

FIG. 7. Fraction of observations in which a pixel is deemed water covered for the BSF domain using the NDWI threshold of 0.1 during the entire 18-yr MODIS MOD09A1 dataset. 

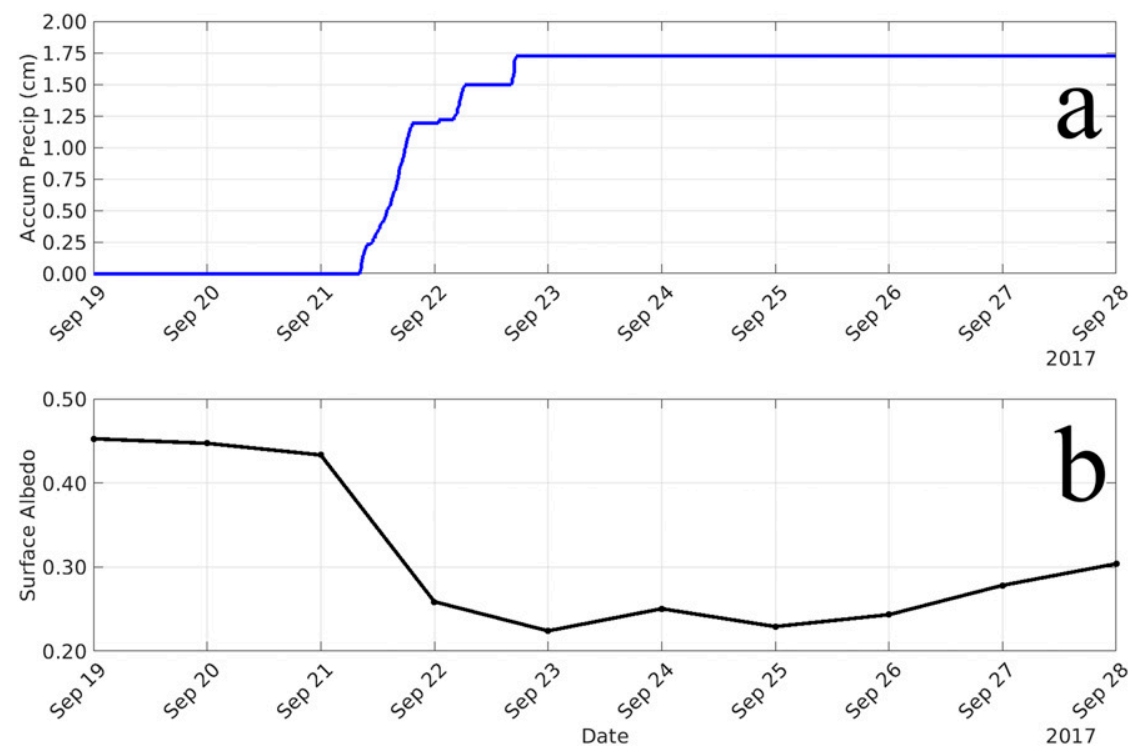

FIG. 8. Flooding and desiccation cycle on the BSF during 19 Sep 2017-29 Sep 2017:

(a) accumulated precipitation ( $\mathrm{cm}$ ) and (b) daily integrated surface albedo.

control, the time-lapse camera images in this instance (e.g., Fig. 10) provided confirmation for the timing of the bore that helps corroborate the shallow depth of the water layer. The time series of wind speed, gust, and direction shown in Fig. 9a highlight that the winds were out of the north preceding the water bore transecting the BFLAT station and sustained at $8 \mathrm{~m} \mathrm{~s}^{-1}$ gusting to
$16 \mathrm{~m} \mathrm{~s}^{-1}$ throughout the duration of the water bore propagating toward the station.

The albedo dropped from 0.36 on 8 October 2017 (dry surface conditions) to 0.31 (flooded surface conditions) on 9 October 2017. The smaller albedo change during this bore event relative to the 0.23 albedo reduction during the large-scale precipitation event presented
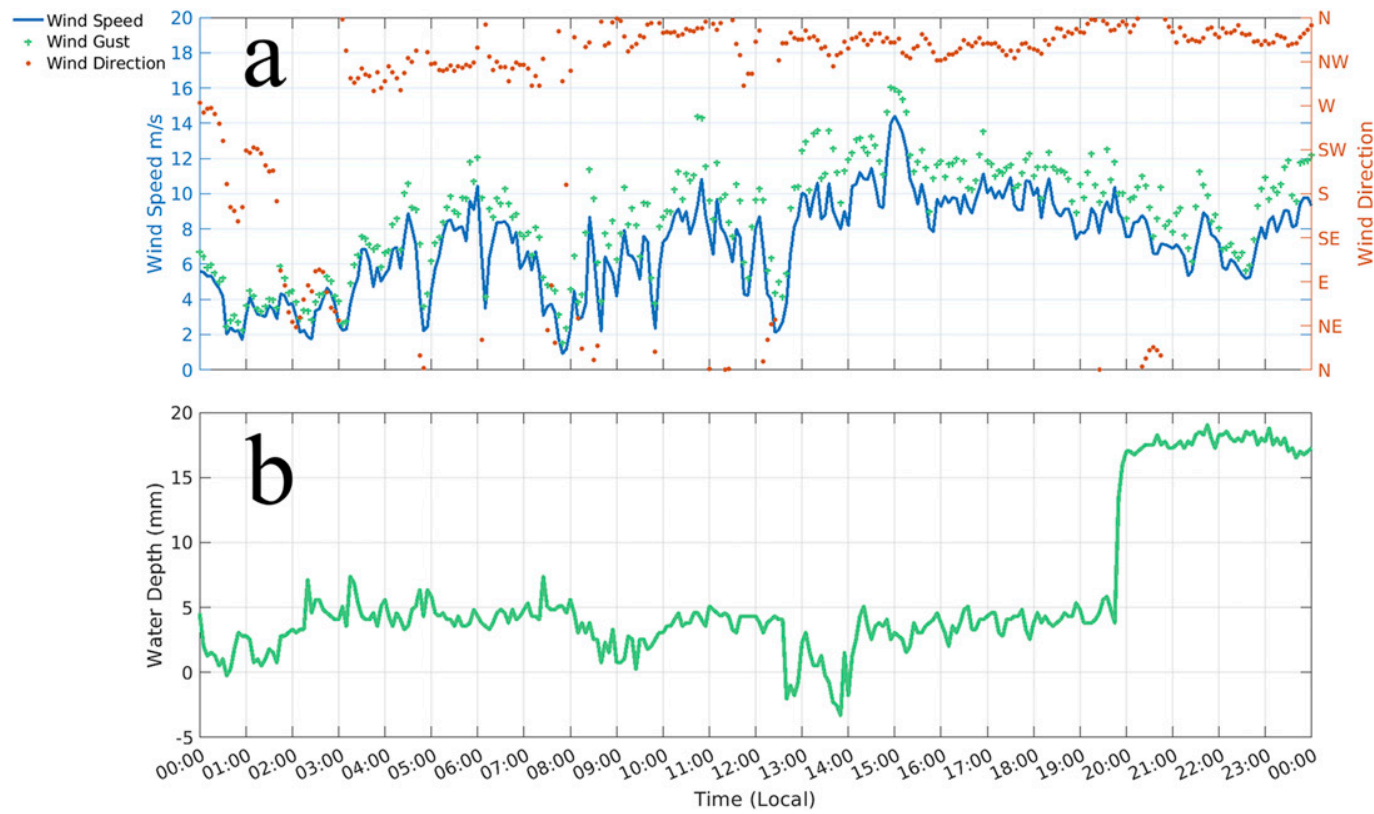

FIG. 9. Variations in selected parameters during a water transport event on the BSF 8 Oct 2017: (a) wind speed and gusts $\left(\mathrm{m} \mathrm{s}^{-1}\right)$ and wind direction and (b) water depth ( $\mathrm{mm}$; relative to the baseline elevation when the sensor was installed). 


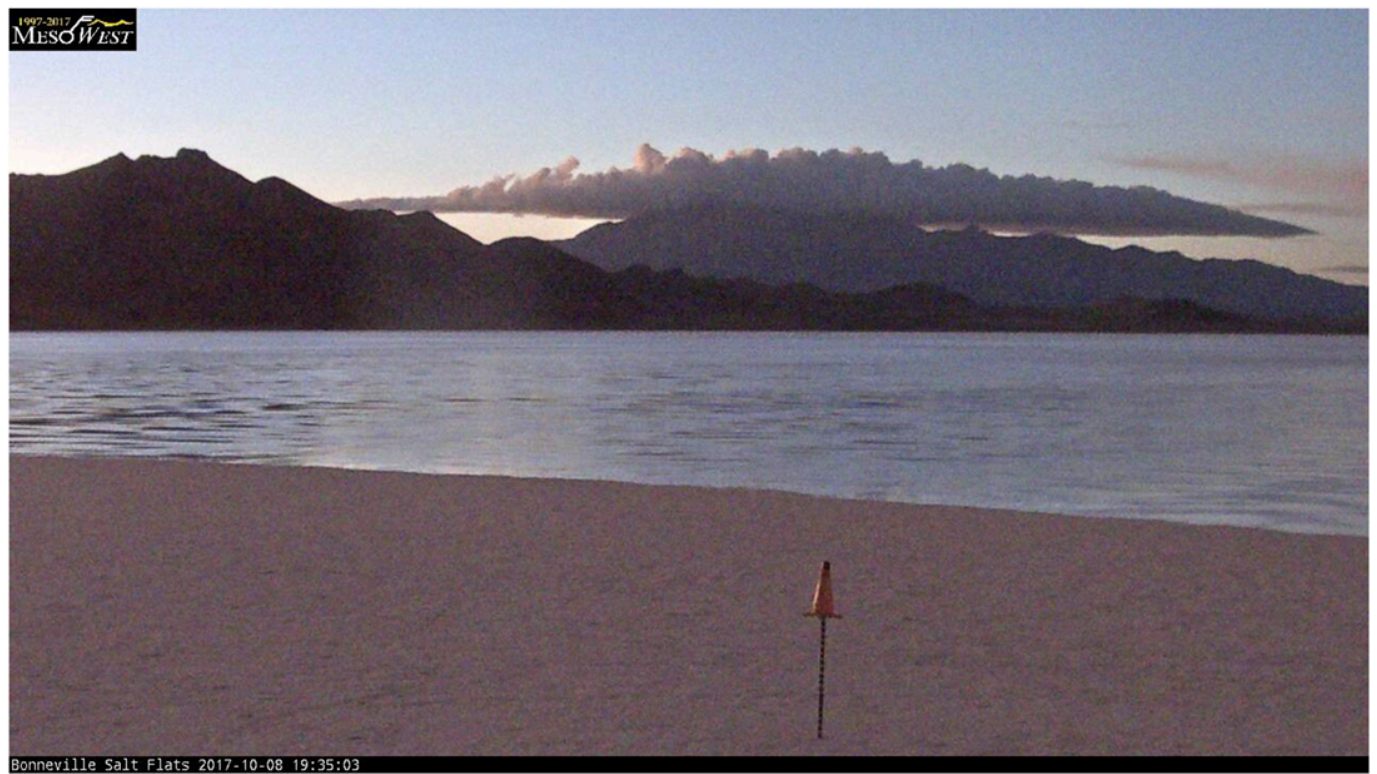

FIG. 10. Shallow water approaching BFLAT station at 0135 UTC 8 Oct 2017.

earlier likely resulted from the modified state of the surface after that prior flooding and desiccation cycle. The shallow depth of the water and cessation of strong northwesterly winds later that morning also reduced the impact on local albedo by limiting the continued transport of water across the surface.

Observed water bore events at BFLAT were primarily forced by northwesterly winds transporting water from the lowest elevations of the BSF. However, if appropriate surface water conditions exist, then water can be transported by winds from other directions. Factors that contribute to bores being observed predominantly in northwesterly flow include the following: 1) bores are common after large-scale precipitation events driven by a cold-frontal passage, which are often followed by northwesterly flow, and 2) the low-lying area of the BSF where surface water is more frequently observed from spatial analysis of the NDWI is located to the northwest of the station (Fig. 7), which allows for a source of water to be transported by the wind.

\section{d. Seasonal albedo changes on the BSF}

Time series of daily surface albedo and accumulated precipitation at BFLAT from October 2016 to June 2017 are presented in Fig. 11 and from June 2017 to June 2018 in Fig. 12. The distinction between the two time periods relates to the change from two independent LICOR solar sensors to the all-in-one Apogee radiation sensor installed on 6 June 2017.

A heavy rainfall episode from 21 to 23 September 2016 (30 mm measured at the nearby Wendover airport
ASOS station) prior to the BFLAT station's installation led to extensive standing water on the BSF until May 2017. The installation was undertaken at the BFLAT site on 29 September 2016 with water depth approaching $25 \mathrm{~mm}$. Hence, the record begins with low albedo that slowly increases during the fall, with occasionally lower albedo likely resulting from additional precipitation and water transport over the site. While the albedo record exhibits considerable day-to-day variability from December 2016 to May 2017, some general trends are evident and consistent with the broader estimate of water coverage on the BSF during this time: 1) lower albedo consistent with the increased water coverage on the BSF from December to early February, 2) a drying period from mid-February to mid-March, 3) sharply reduced albedo likely resulting from increased rainfall and possibly return water flow pumped from the evaporation ponds to the south, and 4) desiccation of the BSF during May.

The installation in June 2017 of the web camera and Apogee all-in-one radiation sensor designed for measuring down- and upwelling solar radiation increases confidence in the estimated albedo since that time. As shown in Fig. 1, high surface albedo $(\sim 0.45)$ during the summer months of 2017 gave way to reduced albedo arising from the September 2017 flooding event discussed earlier (Fig. 8). Large variations in surface albedo are observed as pronounced flooding and desiccation cycles continued throughout the 2017/18 winter driven by precipitation events or wind-driven water transport as discussed in the previous subsections. 

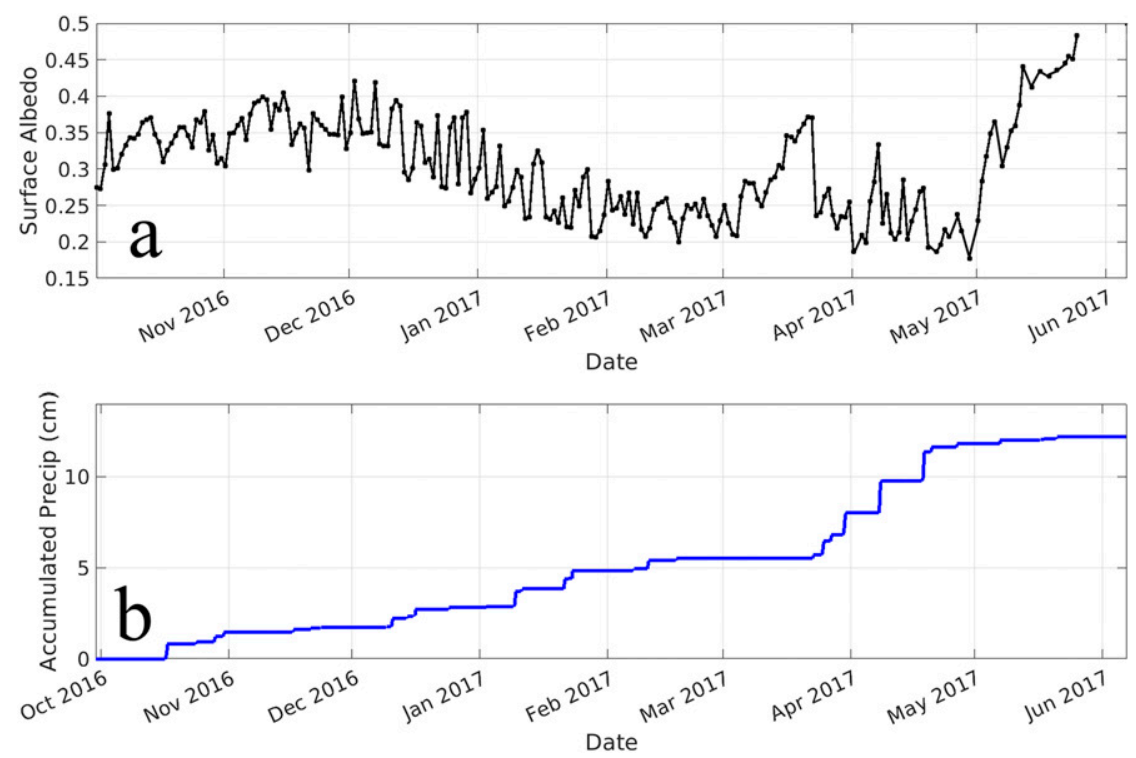

FIG. 11. BFLAT surface albedo and precipitation relationship during October 2016-June 2017: (a) daily integrated surface albedo and (b) accumulated precipitation ( $\mathrm{cm})$.

The NDWI estimate of water coverage for the entire BSF region and spanning the period from fall 2016 through summer 2018 highlights the reduced areal coverage during the 2017/18 winter compared to the previous winter (see Fig. 5). Focusing more narrowly on the immediate vicinity of the BFLAT site, a spatial median value of NDWI in a $1.5 \mathrm{~km} \times 1.5 \mathrm{~km}$ grid box centered around BFLAT was used for the NDWI values to best represent surface conditions at the station as well as averaging the surface albedo at the station on the same 8-day intervals of the NDWI record (Fig. 13). The greater water coverage of the BSF from October 2016 to April 2017 led to local NDWI values greater than zero and low albedo with the highest NDWI and lowest albedo near BFLAT during April 2017. As the surface dried out in May 2017, NDWI decreased and albedo increased. The 8-day averages of albedo during the 2017/18 winter are higher than those during the 2016/17 winter, indicative of less consistent coverage of standing water during the 2017/18 winter.


FIG. 12. As in Fig. 11, but during June 2017-June 2018. 


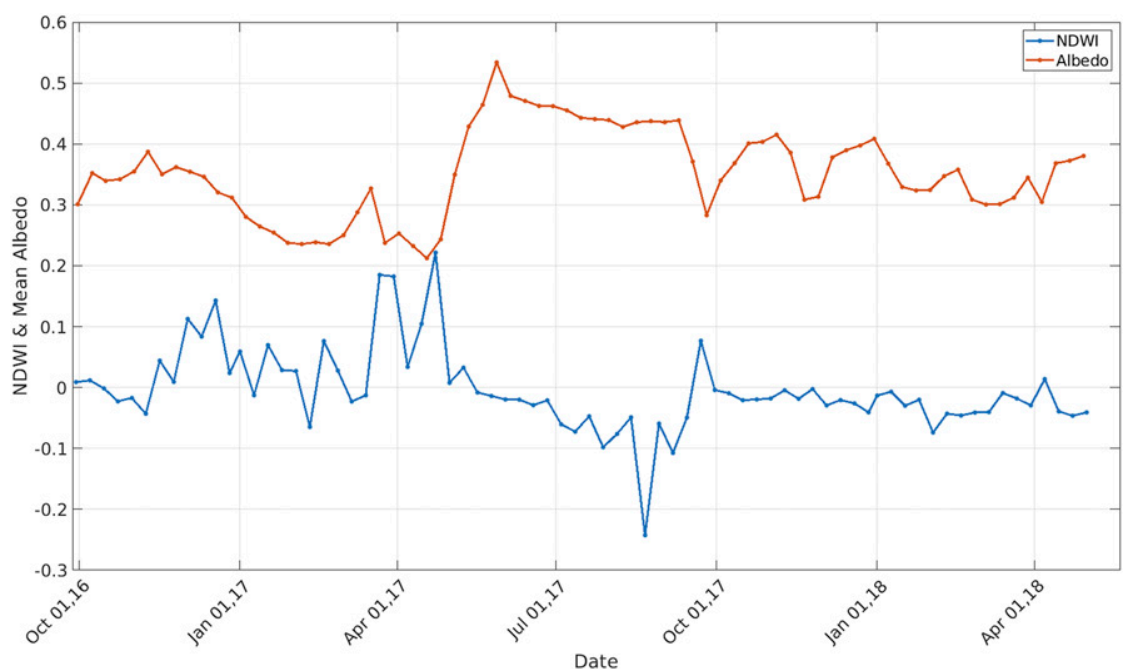

FIG. 13. The 8-day average surface albedo (red) and NDWI (blue) at BFLAT derived as the median NDWI value over a $1.5 \mathrm{~km} \times 1.5 \mathrm{~km}$ gridbox center on BFLAT.

\section{Summary}

An analysis has been presented of the spatial water coverage on the BSF in northern Utah from January 2000 to May 2018 using the NDWI from the MOD09A1 product produced from imagery acquired by the MODIS instrument on board the Terra satellite. Furthermore, ground-based observations on the BSF were used to calculate the surface albedo in relation to changes in surface water coverage.

The fractional area of the BSF domain covered by water ranged from $0 \%$ in the summer to as high as $80 \%$ during winter and late spring but generally does not exceed $40 \%$. Seasonal and subseasonal flooding and desiccation cycles prevalent on the BSF are critical factors for salt crust growth. February is the most likely month for standing water to be observed on the BSF whereas the months of June-August rarely record standing water. September-May is the period when flooding and desiccation cycles are likely.

Surface albedo is greatly affected by soil moisture and flooding and desiccation cycles on the BSF. The daily integrated albedo estimated at BFLAT ranged from 0.2 to 0.45 depending on surface conditions during the 2017-18 flooding and desiccation cycles with lower albedo values corresponding to flooded surface conditions and higher albedo values corresponding to dry surface conditions.

The NDWI data confirm that the most likely areas on the BSF for prolonged periods of standing water are to the northwest of the BFLAT observing station. Postfrontal northwesterly flow occasionally leads to transport of water from that region across the BFLAT site when the surface would otherwise be exposed, causing short-term and abrupt changes in the surface characteristics and making it difficult to know the location and areal extent of an ephemeral lake given the methods of this study.

The MODIS instrument demonstrated the importance of remote sensing in quantifying large spatial variations in surface water. However, future efforts to directly quantify the surface albedo and validate it using ground-based observations are necessary for largescale improvements of land surface datasets. Recent launches of new geostationary satellites such as GOES16 and GOES-17 open the possibilities for monitoring playa surfaces at time scales necessary to capture large variations caused by flooding and desiccation cycles. With the high temporal frequency, albeit reduced spatial resolution, of GOES imagery, water transport on the surface may be observed on the BSF as well. Furthermore, summertime events that alter albedo on shorter time scales due to convective precipitation might be observed. To further extend this research, instrumentation collecting solar radiation, precipitation data, and camera images could be deployed at various playa locations in northern Utah to capture similar albedo changes and compare the differences between the various playa locations. Furthermore, these stations could include additional instrumentation to diagnose surface emissivity and fluxes of heat and moisture below and above the playa surfaces.

Acknowledgments. This work was funded by the National Science Foundation Grant 161747 and by the NOAA/NWS CSTAR program 55500146. Graduate student stipend support was provided by NSF Grant 1617473 and the University of Utah Global Change and 
Sustainability. We greatly appreciate Dr. Brenda Bowen for encouraging our involvement in NSF Grant 1617473 that is studying many interdisciplinary aspects of the Bonneville Salt Flats. We also thank Dr. Erik Crosman, Dr. Alexander Jacques, and others at the University of Utah involved in maintaining the BFLAT station and providing access to the data. We also thank Dr. Sebastian Hoch for his feedback on preliminary results of this study. Computational support and resources from the University of Utah Center for High Performance Computing enabled this work.

\section{REFERENCES}

Barnes, W. L., T. S. Pagano, and V. V. Salomonson, 1998: Prelaunch characteristics of the Moderate Resolution Imaging Spectroradiometer (MODIS) on EOS-AM1. IEEE Trans. Geosci. Remote Sens., 36, 1088-1100, https://doi.org/ 10.1109/36.700993.

Blaylock, B. K., J. D. Horel, and E. T. Crosman, 2017: Impact of lake breezes on summer ozone concentrations in the Salt Lake Valley. J. Appl. Meteor. Climatol., 56,353-370, https://doi.org/ 10.1175/JAMC-D-16-0216.1.

Boussetta, S., E. Balsamo, E. Dutra, A. Beljaars, and C. Albergel, 2015: Assimilation of surface albedo and vegetation states from satellite observations and their impact on numerical weather prediction. Remote Sens. Environ., 163, 111-126, https://doi.org/10.1016/j.rse.2015.03.009.

Bowen, B. B., E. L. Kipnis, and L. W. Raming, 2017: Temporal dynamics of flooding, evaporation, and desiccation cycles and observations of salt crust area change at the Bonneville Salt Flats, Utah. Geomorphology, 299, 1-11, https://doi.org/ 10.1016/j.geomorph.2017.09.036.

Campos, J. C., N. Sillero, and J. C. Brito, 2012: Normalized difference water indexes have dissimilar performances in detecting seasonal and permanent water in the Sahara-Sahel transition zone. J. Hydrol., 464-465, 438-446, https://doi.org/ 10.1016/j.jhydrol.2012.07.042.

Chen, F., and J. Dudhia, 2001: Coupling an advanced land surface-hydrology model with the Penn State-NCAR MM5 modeling system. Part II: Preliminary model validation. Mon. Wea. Rev., 129, 587-604, https://doi.org/10.1175/1520-0493(2001) $129<0587$ :CAALSH $>2.0 . \mathrm{CO} ; 2$.

Chen, X., S. Liang, Y. Cao, T. He, and D. Wang, 2015: Observed contrast changes in snow cover phenology in northern middle and high latitudes from 2001-2014. Sci. Rep., 5, 16820, https:// doi.org/10.1038/srep16820.

Craft, K., 2018: Influence on the atmosphere of short-term variations in the surface state of the Bonnevile Salt Flats, Utah. M.S. thesis, Department of Atmospheric Sciences, University of Utah, 62 pp.

Doña, C., and Coauthors, 2016: Monitoring hydrological patterns of temporary lakes using remote sensing and machine learning models: Case study of La Mancha Húmeda Biosphere Reserve in central Spain. Remote Sens., 8, 618-636, https://doi.org/ 10.3390/rs8080618.

Evans, J. P., X. Meng, and M. F. McCabe, 2017: Land surface albedo and vegetation feedbacks enhanced the millennium drought in south-east Australia. Hydrol. Earth Syst. Sci., 21, 409-422, https://doi.org/10.5194/hess-21-409-2017.

Guo, R., X. Guan, Y. He, Z. Gan, and H. Jin, 2018: Different roles of dynamic and thermodynamic effects in enhanced semi-arid warming. Int. J. Climatol., 38, 13-22, https://doi.org/10.1002/ joc.5155.

Hang, C., D. F. Nadeau, D. D. Jensen, S. W. Hoch, and E. R. Pardyjak, 2016: Playa soil moisture and evaporation dynamics during the MATERHORN Field Program. Bound.-Layer Meteor., 159, 521-538, https://doi.org/10.1007/s10546-015-0058-0.

Henderson-Sellers, A., and M. F. Wilson, 1983: Surface albedo data for climate modeling. Rev. Geophys. Space, 21, 1743-1778, https://doi.org/10.1029/RG021i008p01743.

Horel, J., and Coauthors, 2002: MesoWest: Cooperative mesonets in the western United States. Bull. Amer. Meteor. Soc. 83, 211-226, https://doi.org/10.1175/1520-0477(2002)083<0211: MCMITW $>2.3 . \mathrm{CO} ; 2$

Justice, C. O., and Coauthors, 1998: The Moderate Resolution Imaging Spectroradiometer (MODIS): Land remote sensing for global change research. IEEE Trans. Geosci. Remote Sens., 36, 1228-1249, https://doi.org/10.1109/36.701075.

Kampf, S. K., S. W. Tyler, C. A. Ortiz, J. F. Muñoz, and P. L. Adkins, 2005: Evaporation and land surface energy budget at the Salar de Atacama, northern Chile. J. Hydrol., 310, 236-252, https://doi.org/10.1016/j.jhydrol.2005.01.005.

King, M. D., D. D. Herring, and D. J. Diner, 1995: The Earth Observing System: A space-based program for assessing mankind's impact on the global environment. Opt. Photonics News, 6, 34-39, https://doi.org/10.1364/OPN.6.1.000034.

Kletetschka, G., R. L. B. Hooke, A. Ryan, G. Fercana, E. McKinney, and K. P. Schwebler, 2013: Sliding stones of Racetrack Playa, Death Valley, USA: The roles of rock thermal conductivity and fluctuating water levels. Geomorphology, 195, 110-117, https:// doi.org/10.1016/j.geomorph.2013.04.032.

Li, Q., M. Ma, X. Wu, and H. Yang, 2018: Snow cover and vegetation-induced decrease in global albedo from 2002 to 2016. J. Geophys. Res., 123, 124-138, https://doi.org/10.1002/ 2017JD027010.

Liu, J., and Coauthors, 2009: Validation of Moderate Resolution Imaging Spectroradiometer (MODIS) albedo retrieval algorithm: Dependence of albedo on solar zenith angle. J. Geophys. Res., 114, D01106, https://doi.org/10.1029/ 2008JD009969.

Malek, E., 2003: Microclimate of a desert playa: Evaluation of annual radiation, energy, and water budgets components. Int. J. Climatol., 23, 333-345, https://doi.org/10.1002/joc.873.

_- , and G. E. Bingham, 1990: Evapotranspiration from the margin and moist playa of a closed desert valley. J. Hydrol., 120, 15-34, https://doi.org/10.1016/0022-1694(90)90139-O.

Mallia, D. V., A. Kochanski, D. Wu, C. Pennell, W. Oswald, and J. C. Lin, 2017: Wind-blown dust modeling using a backward-Lagrangian particle dispersion model. J. Appl. Meteor. Climatol., 56, 2845-2867, https://doi.org/10.1175/ JAMC-D-16-0351.1.

Massey, J. D., W. J. Steenburgh, S. W. Hoch, and J. C. Knievel, 2014: Sensitivity of near-surface temperature forecasts to soil properties over a sparsely vegetated dryland region. J. Appl. Meteor. Climatol., 53, 1976-1995, https://doi.org/ 10.1175/JAMC-D-13-0362.1.

,,--- , and D. D. Jensen, 2017: Simulated and observed surface energy fluxes and resulting playa breezes during the MATERHORN field campaigns. J. Appl. Meteor. Climatol., 56, 915-935, https://doi.org/10.1175/JAMC-D-16-0161.1.

McFeeters, S. K., 1996: The use of the Normalized Difference Water Index (NDWI) in the delineation of open water features. Int. J. Remote Sens., 17, 1425-1432, https://doi.org/10.1080/ 01431169608948714. 
Ming, J., Y. Wang, Z. Du, T. Zhang, W. Guo, C. Xiao, and W. Yang, 2015: Widespread albedo decreasing and induced melting of Himalayan snow and ice in the early 21 st century. PLOS ONE, 10, e0126235, https://doi.org/10.1371/ journal.pone. 0126235 .

NASA LP DAAC, 2015a: MCD43A2: MODIS/Terra and Aqua BRDF/Albedo Quality Daily L3 Global 500 m SIN Grid V006. Accessed 1 August 2017, https://doi.org/10.5067/MODIS/ MCD43A2.006.

— 2015b: MCD43A3: MODIS/Terra and Aqua Albedo Daily L3 Global $500 \mathrm{~m}$ SIN Grid V006. Accessed 1 August 2017 , https://doi.org/10.5067/MODIS/MCD43A3.006.

_ 2015c: MOD09A1: MODIS/Terra Surface Reflectance 8-Day L3 Global 500 m SIN Grid V006. Accessed 10 January 2018 , https://doi.org/10.5067/MODIS/MOD09A1.006.

Nicholson, S. E., 2011: Dryland Climatology. 1st ed. Cambridge University Press, $172 \mathrm{pp}$.

Nield, J. M., R. G. Bryant, G. F. S. Wiggs, J. King, D. S. G. Thomas, F. D. Eckardt, and R. Washington, 2015: The dynamism of salt crust patterns on playas. Geology, 43, 31-34, https:// doi.org/10.1130/G36175.1.

G. F. S. Wiggs, J. King, R. G. Bryant, F. D. Eckardt, D. S. G. Thomas, and R. Washington, 2016: Climatesurface-pore-water interactions on a salt crusted playa: Implications for crust pattern and surface roughness development measured using terrestrial laser scanning. Earth Surf. Processes Landforms, 41, 738-753, https://doi.org/ 10.1002/esp.3860.

Steenburgh, J. W., J. D. Massey, and T. H. Painter, 2012: Episodic dust events of Utah's Wasatch Front and adjoining region. J. Appl. Meteor. Climatol., 51, 1654-1669, https://doi.org/ 10.1175/JAMC-D-12-07.1.

Vermote, E. F., and A. Vermeulen, 1999: MODIS Algorithm Technical Background Document Atmospheric Correction Algorithm: Spectral Reflectances (MOD09). 107 pp.

, J. C. Roger, and J. P. Ray, 2015: MODIS Surface Reflectance User's Guide. 35 pp., http://modis-sr.ltdri.org/guide/ MOD09_UserGuide_v1.4.pdf. 